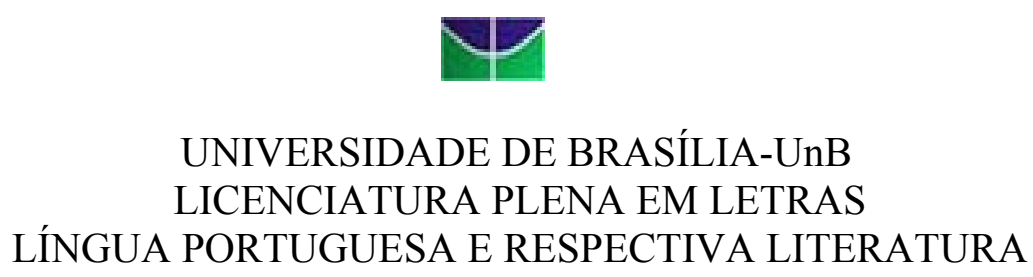

PRICILA DA SILVA ROCHA

AS RELAÇÕES SUBJETIVAS E PREDICATIVAS NAS ORAÇÕES SUBORDINADAS SUBSTANTIVAS.

Brasília- DF

2010. 
PRICILA DA SILVA ROCHA

\title{
AS RELAÇÕES SUBJETIVAS E PREDICATIVAS NAS ORAÇÕES SUBORDINADAS SUBSTANTIVAS.
}

\begin{abstract}
Monografia apresentada à Universidade de Brasília, como requisito parcial para obtenção do título de licenciado em Letras com habilitação em Língua Portuguesa e respectiva Literatura.
\end{abstract}

Orientadora: Prof. ${ }^{a}$ Dra ${ }^{\mathrm{a}}$ : Rozana Reigota Naves.

Brasília- DF 


\section{DEDICATÓRIA}

Ao meu esposo, Rafael, pelas angústias e preocupações que passou por minha causa nos momentos que passei horas pesquisando, pelo amor, carinho e estímulo que me ofereceu, dedico-lhes esse trabalho como gratidão. 
AGRADECIMENTO

Agradeço a ajuda prestimosa de minha orientadora, Rozana, pela paciência e atenção com que sempre me acolheu e por compartilhar seus conhecimentos. Agradeço a meus colegas pelo apoio e estímulo. 
O sucesso nasce do querer, da determinação e persistência em se chegar a um objetivo. Mesmo não atingindo o alvo, quem busca e vence obstáculos, no mínimo fará coisas admiráveis.

José de Alencar 


\section{SUMÁRIO}

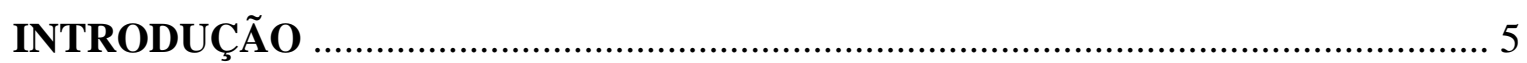

1 ASPECTOS TEÓRICOS SOBRE A APRENDIZAGEM SIGNIFICATIVA............ 6

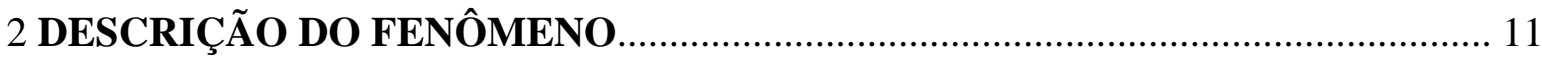

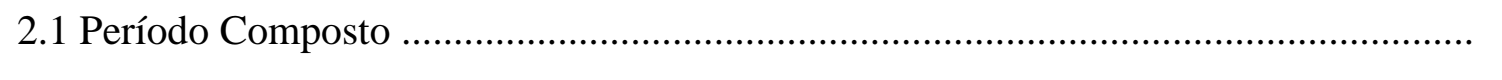

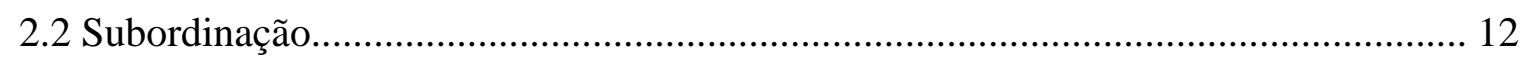

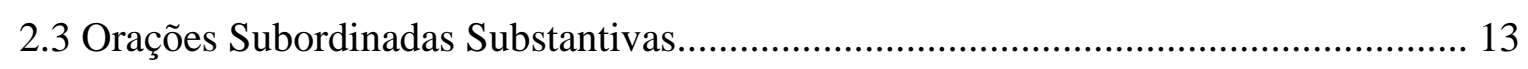

2.4 Orações Subordinadas Substantivas Subjetivas e Predicativas................................... 15

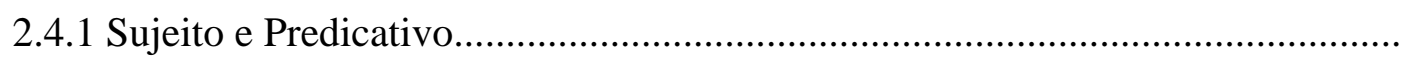

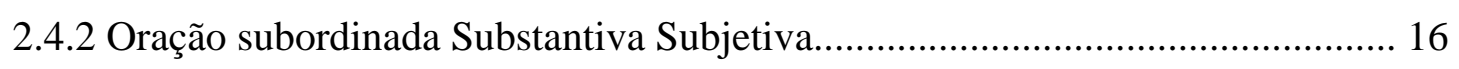

2.4.3 Oração Subordinada Substantiva Predicativa.................................................. 18

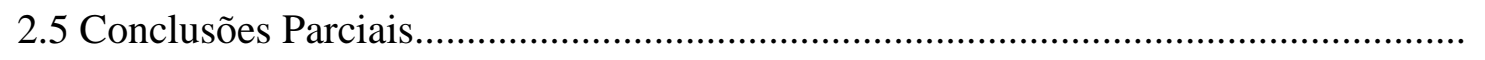

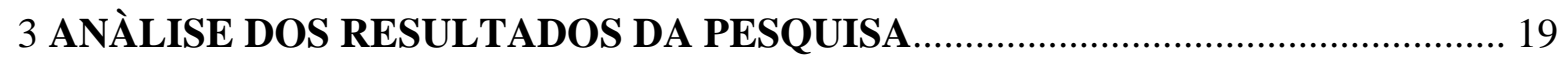

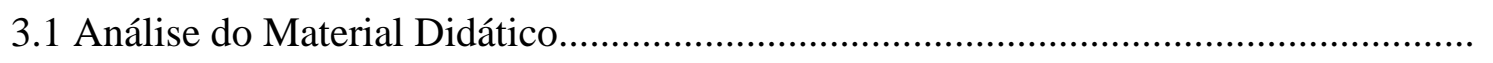

3.2 Análise da Aplicação Orientada de Exercício Linguístico ......................................... 20

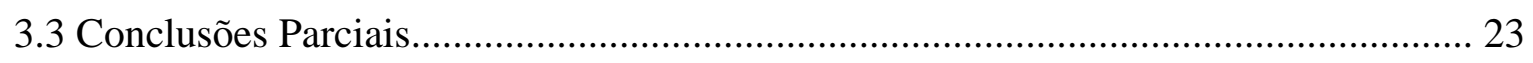

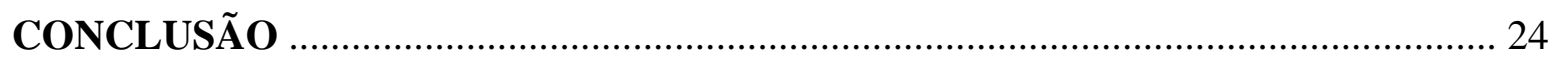

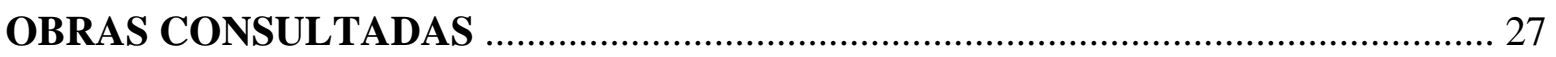




\section{INTRODUÇÃO}

Neste trabalho, serão discutidas questões relativas ao ensino da classificação das orações subordinadas substantivas em subjetivas e predicativas, tendo em vista a maneira básica de inserir constituintes dentro de outros constituintes. Essa discussão será associada às teorias de aprendizagem significativa, cujos pressupostos se pautam na organização e integração dos conteúdos, na estrutura cognitiva do aluno, o que acontece quando ele recebe uma informação e associa essa informação com algo que aprendeu anteriormente, tornando assim a informação em conhecimento.

Como as orações subordinadas substantivas subjetivas se confundem com as predicativas, pretende-se analisar a classificação dessas orações, demonstrando-se as diferenças estruturais entre elas e a relação que essas diferenças têm com os problemas de aprendizagem relativos a esse conteúdo.

Supõe-se que os alunos tendem a confundir a classificação das orações substantivas subjetivas e predicativas porque não atentam para as suas estruturas, sucessivamente porque esses conceitos não estão bem explicitados nos materiais didáticos e porque os aprenderam de forma mecânica. Acredita-se que não ocorre aprendizagem significativa no primeiro contato com esse conteúdo.

A pesquisa é de caráter investigativo e a metodologia propõe fazer a análise dos livros didáticos do nível médio utilizados pelas escolas em que os sujeitos pesquisados estão matriculados, além de propor atividades aos alunos entrevistá-los com o objetivo de identificar as dificuldades que eles encontram na aprendizagem desse conteúdo. 


\section{CAPÍTULO 1}

\section{Aspectos Teóricos sobre Aprendizagem Significativa}

Para Jean Piaget (1973), todos os indivíduos constroem as mesmas estruturas cognitivas, ou passam pelos mesmos estágios de desenvolvimento, na mesma ordem de sucessão, independentemente da cultura. $\mathrm{O}$ caminho percorrido é sempre o mesmo. Isso se deve ao fato de que todos os seres partem do mesmo ponto - as estruturas inatas de cada indivíduo que obedecem a um fator endógeno de regulação, ou equilibração, que envolve dois pólos: um pólo de adaptação externa, pelo qual o indivíduo integra novos elementos do meio a suas estruturas cognitivas (processo conhecido como assimilação) e, simultaneamente, as ajusta a esse meio (processo de acomodação) - e um pólo de organização interna, pelo qual se dá a relação entre a parte integrada e o todo já possuído.

A adaptação, conforme definida por Piaget, assim como o próprio desenvolvimento da inteligência, ocorre através da assimilação e da acomodação. Os esquemas de assimilação vão se modificando, configurando os estágios de desenvolvimento. Nesse sentido, o professor, que é um mediador desse processo, deve seguir os esquemas de assimilação do indivíduo, propondo atividades desafiadoras que provoquem desequilíbrios e reequilibrações sucessivas, promovendo a descoberta e a construção do conhecimento.

Para construir o conhecimento, as concepções infantis combinam-se às informações advindas do meio, na medida em que o conhecimento não é concebido apenas como sendo descoberto espontaneamente pela criança, nem transmitido de forma mecânica pelo meio exterior ou pelos adultos, mas, como resultado de uma interação, na qual o sujeito é sempre um elemento ativo, que procura ativamente compreender o mundo que o cerca, e que busca resolver as interrogações que esse mundo provoca.

Segundo Piaget, a aprendizagem ocorre quando se usa um método que leve ao descobrimento por parte do aluno, que não deve receber passivamente as informações 
por intermédio do professor, porque a aprendizagem é um processo construído internamente, é um processo de reorganização cognitiva. Os conflitos cognitivos são importantes para o desenvolvimento da aprendizagem, pois os conteúdos não são concebidos como fins em si mesmos, mas como instrumentos que servem ao desenvolvimento evolutivo natural.

Uma maneira adequada de ampliar e/ou modificar as estruturas do aluno consiste, nessa teoria, em provocar discordâncias ou conflitos cognitivos que representem desequilíbrios a partir dos quais, mediante atividades, o aluno consiga reequilibrar-se, superando a discordância e reconstruindo o conhecimento. Para isso, é necessário que as aprendizagens não sejam excessivamente simples, o que provocaria frustração ou rejeição.

A teoria da assimilação de David Paul Ausubel (1982), ou teoria da aprendizagem significativa, é uma teoria cognitivista e procura explicar os mecanismos internos que ocorrem na mente humana com relação ao aprendizado e à estruturação do conhecimento. Contemporâneo de Piaget, Ausubel define que aprendizagem consiste na “ampliação" da estrutura cognitiva, através da incorporação de novas idéias a ela. Dependendo do tipo de relacionamento que se tem entre as idéias já existentes nessa estrutura cognitiva e as novas que se estão internalizando, pode ocorrer um aprendizado que varia do mecânico ao significativo. Como Piaget, Ausubel acredita no valor da aprendizagem por descoberta.

David Ausubel (1982) trabalhou com três tipos de aprendizagem que se complementam para chegar a uma aprendizagem significativa:

a. Cognitiva: armazenamento organizado de informações na mente do ser que aprende.

b. Afetiva: sinais internos ao indivíduo, que podem ser identificados com experiências tais como: prazer, dor, alegria, dentre outros. Em algumas vezes essa experiência afetiva acompanha a cognitiva.

c. Psicomotora: respostas musculares adquiridas por meio de treino e prática, algumas vezes acompanhadas de experiência cognitiva.

A aprendizagem significativa tem lugar quando as novas idéias vão se relacionando de forma não-arbitrária e substantiva com as idéias já existentes. Por "nãoarbitrariedade" entende-se que existe uma relação lógica e explícita entre a nova idéia e 
alguma(s) outra(s) já existente(s) na estrutura cognitiva do indivíduo. Assim, por exemplo, entender o conceito do termômetro só será de fato significativo para o indivíduo, se de alguma forma houver uma clara relação entre o termômetro e o conceito de temperatura.

Além de não-arbitrária, para ser significativa, a aprendizagem precisa ser também substantiva, ou seja, uma vez aprendido determinado conteúdo dessa forma, o indivíduo conseguirá explicá-lo com as suas próprias palavras. Assim, um mesmo conceito pode ser expresso em linguagem sinônima e transmitir o mesmo significado (Aragão, 1976, p. 21).

Como exemplo desse tipo de processo, se o aluno aprende significativamente que o cão é um mamífero, ele deverá ser capaz de expressar isso de diversas formas, como: "o filhote de cachorro mama de sua mãe" ou "o cachorro é um animal que, como nós, mama quando é filhote". A "substantividade" do aprendizado significa, então, que o aprendiz apreendeu o sentido, o significado daquilo que se ensinou, de modo que pode expressar esse significado com as mais diversas palavras.

Para o autor, o objetivo maior do ensino é que todas as idéias sejam aprendidas de forma significativa. Isso porque é somente desse jeito que as novas idéias serão "armazenadas" por bastante tempo e de maneira estável. Além disso, a aprendizagem significativa permite ao aprendiz o uso do novo conceito de forma inédita, independentemente do contexto em que o conteúdo foi primeiramente aprendido.

O extremo oposto da aprendizagem significativa é a aprendizagem mecânica. Nesse caso, as novas idéias não se relacionam de forma lógica e clara com nenhuma idéia já existente na estrutura cognitiva do sujeito, porém são "decoradas". Dessa maneira, elas são armazenadas de forma arbitrária, o que não garante flexibilidade no seu uso, nem longevidade.

Como conseqüência dessa não-flexibilidade, o aprendizado não é substantivo, o indivíduo não é capaz de expressar o novo conteúdo com linguagem diferente daquela com que foi primeiramente aprendido. De fato, ele não aprendeu o significado, o sentido do novo material, mas tão-somente decorou a seqüência de palavras que o definia. No exemplo dado acima - de o cachorro ser um mamífero -, o indivíduo será incapaz de fazer a relação entre o cachorro e o ser humano, ou mesmo com o fato de que os mamíferos mamam, o que não aconteceria na aprendizagem mecânica.

Quando o conteúdo escolar a ser aprendido não consegue ligar-se a algo já conhecido, ocorre o que Ausubel chama de aprendizagem mecânica, ou seja, quando as 
novas informações são aprendidas sem interagir com conceitos relevantes existentes na estrutura cognitiva. Assim, a pessoa decora fórmulas, leis, mas as esquece após a avaliação. Quanto mais se relaciona o novo conteúdo de maneira substancial e não arbitrária com algum aspecto da estrutura cognitiva prévia que for relevante para $\mathrm{o}$ aluno, mais próximo se está da aprendizagem significativa. Quanto menos se estabelece esse tipo de relação, mais próximo se está da aprendizagem mecânica ou repetitiva.

É importante ressaltar que, apesar de Ausubel ter enfatizado a aprendizagem significativa, ele compreendia que no processo de ensino-aprendizagem existem circunstâncias em que a aprendizagem mecânica era inevitável. No ensino de História, por exemplo, conhecer e entender os eventos que se sucederam no surgimento e desenvolvimento do Império Romano requer, muitas vezes, que se saiba os nomes de diversas de suas instituições e personagens principais, o que é tipicamente um aprendizado mecânico.

Para haver aprendizagem significativa são necessárias duas condições. Em primeiro lugar, o aluno precisa ter uma disposição para aprender: se o indivíduo quiser memorizar o conteúdo arbitrária e literalmente, então a aprendizagem será mecânica. Em segundo, o conteúdo escolar a ser aprendido tem de ser potencialmente significativo, ou seja, ele tem que ser lógico e psicologicamente significativo: o significado lógico depende somente da natureza do conteúdo, e o significado psicológico é uma experiência que cada indivíduo tem. Cada aprendiz faz uma filtragem dos conteúdos que têm significado ou não para si próprio.

Segundo a teoria de Ausubel, na aprendizagem significativa há três vantagens essenciais em relação à aprendizagem memorística. Em primeiro lugar, o conhecimento que se adquire de maneira significativa é retido e lembrado por mais tempo. Em segundo, aumenta-se a capacidade de aprender outros conteúdos de uma maneira mais fácil, mesmo se a informação original for esquecida. E, em terceiro, uma vez esquecida, a informação inicial facilita a aprendizagem seguinte - a "reaprendizagem", para dizer de outra maneira.

Conforme a teoria de Ausubel, os principais conceitos relativos à aprendizagem se articulam esquematicamente da seguinte forma (Faria, 1989, p 7): 


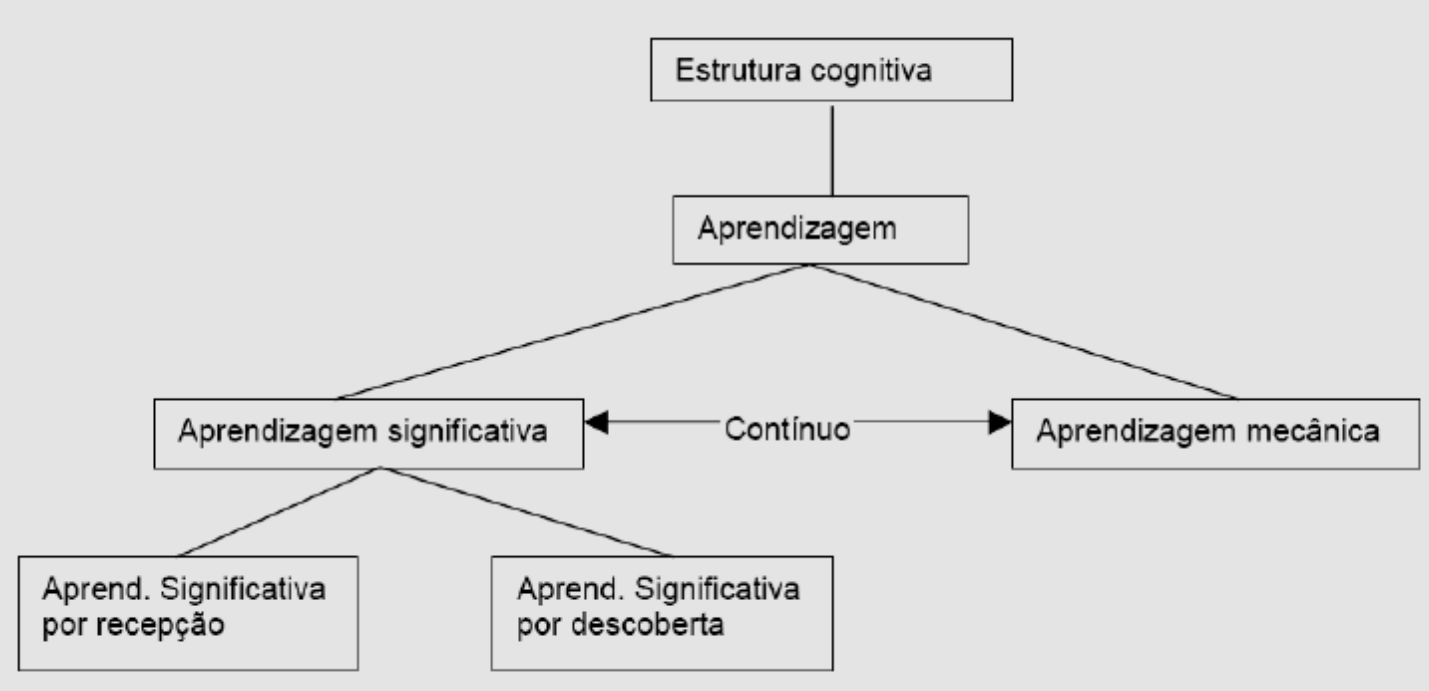

Segundo o autor (apud Faria, 1989, p. 8), a estrutura cognitiva é o conteúdo total e organizado de idéias de um dado indivíduo; ou, no contexto da aprendizagem de certos assuntos, refere-se ao conteúdo e organização de suas idéias naquela área particular de conhecimento. Ou seja, a ênfase que se dá é na aquisição, armazenamento e organização das idéias no cérebro do indivíduo.

Cabe ainda ressaltar que, conforme a teoria apresentada, a aprendizagem significativa pode se processar tanto por descoberta quanto por recepção:

a. descoberta: o aluno deve aprender "sozinho", deve descobrir algum princípio, relação, lei,..., como pode acontecer na solução de um problema.

b. recepção: recebe-se a informação pronta (como em uma aula expositiva) e o trabalho do aluno consiste em atuar ativamente sobre esse material, a fim de relacioná-lo a idéias relevantes disponíveis em sua estrutura cognitiva.

Para Ausubel, a estrutura cognitiva de cada indivíduo é extremamente organizada e hierarquizada, no sentido que as várias idéias se encadeiam de acordo com a relação que se estabelece entre elas. Além disso, é nessa estrutura que se ancoram e se reordenam novos conceitos e idéias que o indivíduo vai progressivamente internalizando, aprendendo.

Em resumo, a aprendizagem é muito mais significativa à medida que o novo conteúdo é incorporado às estruturas de conhecimento de um aluno e adquire significado para ele a partir da relação com seu conhecimento prévio. Ao contrário, ela se torna mecânica ou repetitiva. 


\section{CAPÍTULO 2}

\section{Descrição do Fenômeno}

Neste capítulo será discutido o processo pelo qual, tradicionalmente, distinguemse duas maneiras básicas de inserir constituintes dentro de outros constituintes: a subordinação e a coordenação. Essa dicotomia representa uma simplificação e está longe de dar conta de todos os fatos, mas servirá como ponto de partida para a exposição, de modo que vou começar conceituando esses dois processos, porém vou estudar mais detalhadamente a subordinação.

\subsection{Período Composto}

Período é uma frase organizada em orações. No período simples, existe apenas uma oração, chamada absoluta, e, no período composto, existem duas ou mais orações. Essas orações podem se relacionar por meio de dois processos sintáticos diferentes: a subordinação e a coordenação.

As orações coordenadas estão ligadas por conectores chamados conjunções coordenativas, que marcam o tipo de relação semântica entre os conteúdos de pensamento designados em cada uma das orações sintaticamente independentes, como mostram os exemplos a seguir, em que as orações de cada período expressam uma relação de semântica de oposição e de conclusão, respectivamente:

(1) Li o livro, mas não gostei.

(2) Choveu muito, portanto, o jogo foi adiado.

Já as orações subordinadas são ligadas por conjunções subordinativas e funcionam como termo de outra oração. Como o tema de pesquisa deste trabalho se 
refere a tipos de orações subordinadas, esse conceito será mais desenvolvido na próxima seção.

\subsection{Subordinação}

Subordinação é um conceito amplo segundo o qual um termo atua como determinante de outro termo. Essa relação se verifica, por exemplo, entre um verbo e seus complementos: os complementos são determinantes do verbo, integrando sua significação. Conseqüentemente, o objeto direto e o objeto indireto são termos subordinados ao verbo, que é o termo subordinante.

No período composto por subordinação, considera-se subordinada a oração que desempenha função de termo de outra oração, o que equivale a dizer que existem orações que atuam como determinantes de outras orações, como no exemplo a seguir, em que a segunda oração funciona como objeto direto da primeira:

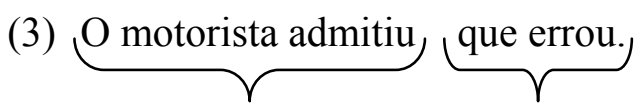

Oração Principal Or. Subord. Subst. Objetiva Direta

Nesse sentido, a subordinação corresponde ao fato de uma oração passar a funcionar como parte de outra oração. As orações sem autonomia gramatical, isto é, que funcionam como termos essenciais, integrantes ou acessórios de outra oração, chamamse subordinadas, enquanto a oração que contém a declaração principal do período, regese por si e não desempenha nenhuma função sintática em outra oração do período chama-se oração principal. As subordinadas têm sua existência dependente da oração principal e desempenham sempre uma função sintática.

As orações subordinadas são marcadas pela presença de certos elementos sintáticos ou morfológicos, que as caracterizam como subordinadas, embora esses termos nem sempre sejam propriamente parte da subordinada. Esses elementos têm também uma função semântica, de modo que não seriam dispensáveis. As marcas explícitas de subordinação são: as conjunções, os relativos, as marcas de interrogativa indireta, as desinências do modo subjuntivo, as desinências das formas nominais do verbo. 
As orações subordinadas podem ser substantivas (se desempenham funções associadas aos substantivos, como em (4), em que a oração subordinada representa o Complemento Nominal), adjetivas (se desempenham a função de adjunto adnominal, que é típica dos adjetivos, como em (5)) ou adverbiais (se desempenham a função de adjunto adverbial, como em (6)):

(4) Está convicta de que o ama.

(5) A exposição de arte moderna que visitamos foi um sucesso.

(6) Emocionava-se à proporção que via o filme.

Quanto à forma, elas podem ser desenvolvidas (apresentam verbos numa das formas finitas - tempos do indicativo, subjuntivo, imperativo - e apresentam normalmente conjunção ou pronome relativo) ou reduzidas (apresentam verbos numa das formas nominais - infinitivo, gerúndio, particípio - e não apresentam conjunções nem pronomes relativos, podendo apresentar preposição). Em (7) tem-se um exemplo de oração desenvolvida e em (8), um exemplo de oração reduzida de infinitivo:

(7) É conveniente que aceite a proposta.

(8) É conveniente aceitar a proposta.

Serão estudadas, neste trabalho, as orações subordinadas substantivas, especificamente as orações subjetivas e as predicativas.

\subsection{Orações Subordinadas Substantivas}

Como dissemos anteriormente, as orações subordinadas substantivas aparecem inseridas no período composto exercendo funções próprias do substantivo. Elas são classificadas de acordo com a função sintática que exercem em relação à oração principal: 
Oração Subord. Substantiva Função no Período Composto

$\begin{array}{ll}\text { Subjetiva } & \text { Sujeito da oração principal } \\ \text { Objetiva direta } & \text { Objeto direto do verbo da oração principal } \\ \text { Objetiva indireta } & \text { Objeto indireto do verbo da oração principal } \\ \text { Predicativa } & \text { Predicativo do sujeito da oração principal } \\ \text { Completiva nominal } & \text { Complemento nominal de um nome da oração principal } \\ \text { Apositiva } & \text { Aposto de um nome da oração principal }\end{array}$

As orações subordinadas substantivas desenvolvidas possuem verbos conjugados e são introduzidas pelas conjunções integrantes que ou se, ressaltando-se que a conjunção que pode vir precedida de preposição conforme exerça função que necessite desse índice As orações substantivas desenvolvidas também podem ser iniciadas por outros tipos de palavras como os pronomes interrogativos (que, quem, qual), e os advérbios interrogativos (por que, quando, onde, como). As orações substantivas reduzidas não são introduzidas por conjunções e possuem verbos nas formas nominais. Os exemplos a seguir, que trazem orações subordinadas objetivas diretas, ilustram esses fatos:

\section{Conjunção Integrante}

(9) O aluno disse $\overbrace{\text { que entendeu a explicação. }}$

$$
\text { Conjunção Integrante }
$$

(10) Perguntam $\overbrace{\text { se }}^{h}$ vai haver aula.

Pronome Interrogativo

(11) Sei $\overbrace{\text { qual }}^{\text {foi o autor. }}$

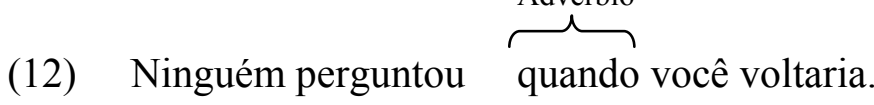

$$
\text { Verbo na forma nominal (infinitivo) }
$$

(13) O motorista decidiu acatar as novas mudanças.

Delimitando o meu objeto de estudo, apresentarei as orações subordinadas substantivas subjetivas e as predicativas, mostrando suas estruturas básicas. 


\subsection{Orações Subordinadas Substantivas Subjetivas e Predicativas}

A oração subordinada substantiva subjetiva exerce a função de sujeito da oração principal e a predicativa exerce a função de predicativo do sujeito da oração principal. É conveniente retomar as noções de sujeito e de predicativo do sujeito.

\subsubsection{Sujeito e Predicativo}

Uma oração é constituída por duas partes, uma delas é o sujeito e a outra é tudo aquilo que se diz do sujeito - o predicado.

Sujeito é o ser sobre o qual se faz uma declaração e também o elemento com o qual o verbo estabelece concordância. O sujeito classifica-se como simples quando tem um único núcleo, composto quando tem dois ou mais núcleos, elíptico quando não está explicitamente apresentado na oração (podendo ser reconhecido pela desinência do verbo), ou indeterminado quando se desconhece quem executa a ação ou não há interesse no seu conhecimento (casos em que o sujeito não vem expresso na oração nem pode ser identificado o verbo se apresenta na $3 .^{a}$ pessoa do plural ou na $3 .^{\mathrm{a}}$ pessoa do singular com o pronome se). Deve-se atentar para não confundir sujeito indeterminado com oração sem sujeito, pois nesta não existe sujeito, ou seja, o predicado não é atribuível a nenhum agente, enquanto naquele há um sujeito que o falante, por não querer ou não poder, não declara. Existem no idioma alguns verbos que apresentam uma particularidade sintática: Eles não admitem sujeito. Tais verbos, denominados impessoais, formam as orações sem sujeito. A função sintática de sujeito pode ser exercida por substantivos, pronomes e palavras substantivadas.

O predicado, da mesma forma que o sujeito, tem um núcleo, isto é, um elemento principal. Dependendo do tipo de núcleo o predicado pode ser: nominal, verbal ou verbo-nominal. Nos predicados nominais (e eventualmente nos verbo-nominais), encontraremos o predicativo do sujeito. O predicativo refere determinado atributo ao sujeito, e é função exercida por pronomes, substantivos, adjetivos, numerais e por oração subordinada substantiva predicativa.

O predicado nominal é formado por um verbo de ligação + predicativo. O verbo de ligação pode expressar: estado permanente, estado transitório, mudança de estado, continuidade de estado e aparência de estado; sua função, nesse tipo de predicado, é 
ligar o sujeito ao predicativo do sujeito, que é o núcleo do predicado nominal, como nos exemplos:

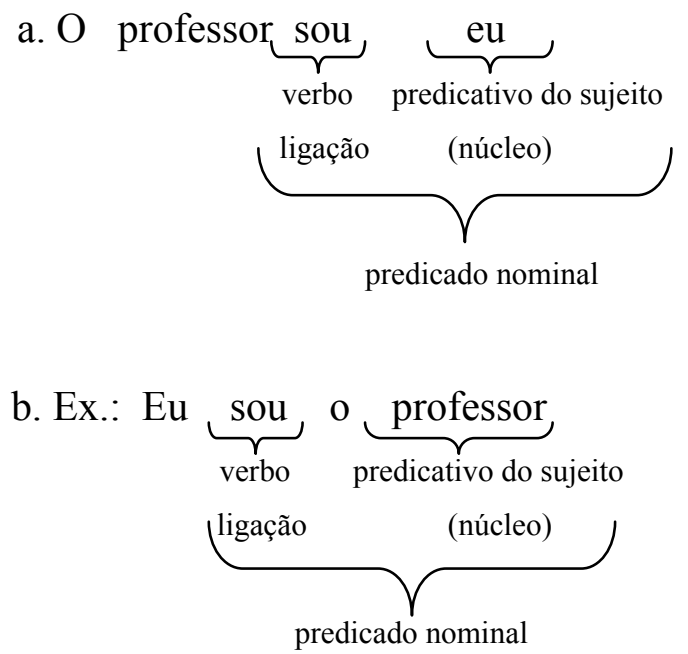

Os predicados nominais são simétricos, principalmente quando apresentam o verbo ser, o que pode causar confusão na identificação do sujeito e do predicativo do sujeito, pois o que determina qual termo é sujeito e qual termo é predicativo do sujeito é a ordem e não a concordância, como ilustra o exemplo (14); há, portanto, um problema de análise sintática decorrente dessa simetria dos predicados nominais, o qual tem impacto sobre a classificação das orações subordinadas substantivas e predicativas.

\subsubsection{Oração Subordinada Substantiva Subjetiva}

Existem três estruturas básicas de oração principal às quais pode se associar uma oração substantiva subjetiva (15), como mostra o esquema em (16):

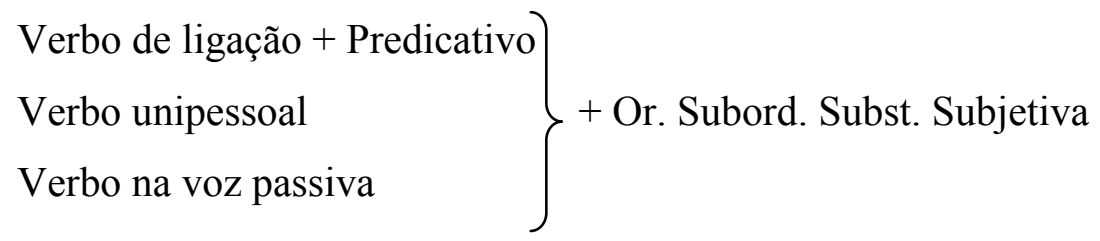


(16) Período Simples: $\overbrace{\text { Era }}^{\mathrm{VL}} \overbrace{\text { indispensável }}^{\text {Predicativo }} \overbrace{\text { seu regresso. }}^{\text {Sujeito }}$

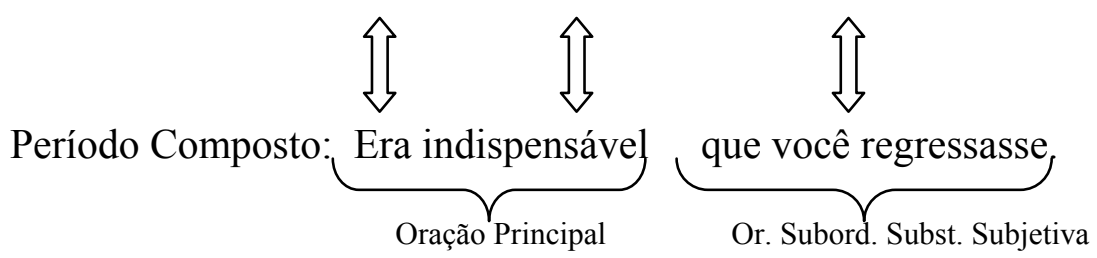

Como a oração substantiva exerce o papel de um termo que falta à oração principal, dentro da principal não há nenhum termo de mesma função que a oração substantiva, ou seja, não há sujeito dentro dos limites da oração principal. Toda vez em que a oração principal apresentar verbo de ligação + predicativo, a oração subordinada substantiva será subjetiva, ou seja, funcionará como o termo que falta na oração principal. É o que ocorre com verbos unipessoais como no exemplo (17):

(17) Per. Simples: Na ata da reunião não $\overbrace{\text { constava }} \overbrace{\text { a presença das mulheres. }}^{V}$.

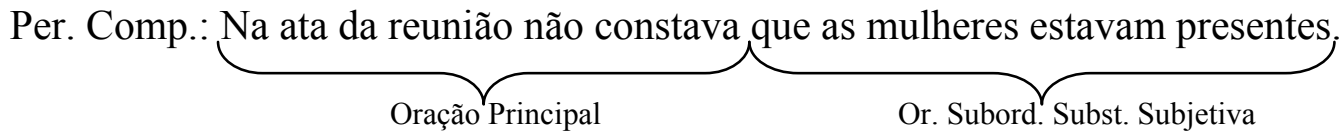

Verbos unipessoais seguidos de conjunção integrante (que/se) só se empregam na $3^{\mathrm{a}}$ pessoa do singular. Os unipessoais mais comuns são: constar, convir, parecer, importar, interessar, suceder, acontecer.

Nos exemplos abaixo, o verbo está na voz passiva analítica (18), mas pode também ocorrer na voz passiva pronominal (19). O paciente, representado nos períodos compostos pela oração subordinada, funciona como sujeito:

(18) Per. Simples: Foi anunciado ontem o aumento do preço dos laticínios.

Per. Comp.: Foi anunciado ontem que o preço dos laticínios aumentará

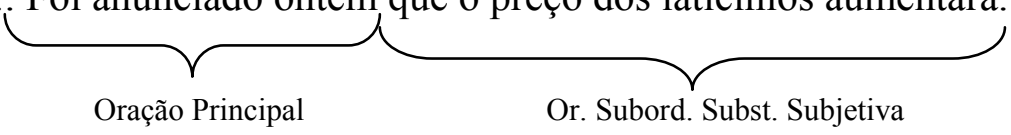

(19) Per. Comp.; Anunciou-se ontem que o preço dos laticínios aumentará, Oração Principal Or. Subord. Subst. Subjetiva 
Funciona como predicativo do sujeito da oração principal, em uma construção de predicado nominal, que apresenta a seguinte estrutura básica: sujeito + verbo de ligação + Oração subordinada substantiva predicativa.

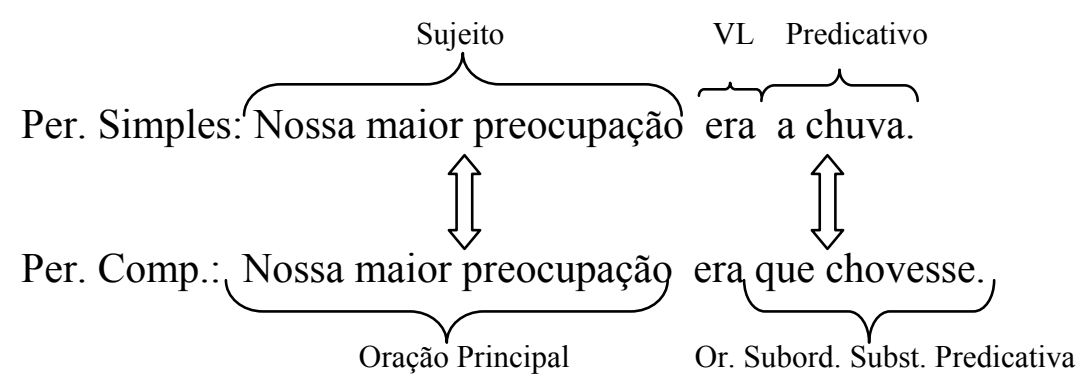

\subsection{Conclusões Parciais}

Apesar da semelhança estrutural, a oração predicativa não se confunde com a oração subjetiva, como ilustram os exemplos:

(21) É certo que Portugal não ganhará do Brasil. (subjetiva)

(22) O certo é que Portugal não ganhará do Brasil. (predicativa)

Se o verbo de ligação estiver antes do adjetivo, a oração subordinada, que estará depois do adjetivo (predicativo), será subjetiva; se o verbo de ligação estiver depois do substantivo (sujeito), a oração subordinada, que estará depois do verbo de ligação, será predicativa.

Percebe-se que a classificação das orações subordinadas decorre da combinação da função sintática que exercem em relação à oração principal. $\mathrm{O}$ período composto deve ser analisado de acordo com a estrutura da oração absoluta (período simples) e, com base no papel que desempenham os termos no período simples, define-se a função que desempenham no período composto, função essa que se traduz na classificação das orações como substantivas. 


\section{CAPÍTULO 3}

\section{Análise dos Resultados da Pesquisa}

Neste capítulo será apresentada a análise do material didático frequentemente utilizado como instrumento lingüístico para o ensino de língua portuguesa no nível médio, especificamente, os livros didáticos adotados pelas escolas regulares em que os sujeitos desta pesquisa estão matriculados.

Também serão apresentados os resultados da aplicação orientada de um exercício de classificação de orações, cujo objetivo é o de verificar as dificuldades dos estudantes com as orações subordinadas substantivas subjetivas e predicativas.

\subsection{Análise do Material Didático}

Os instrumentos linguísticos analisados se intitulam: Gramática em Textos (Leila Lauar Sarmento, 2005); Gramática Reflexiva: Texto, Semântica e Interação (William Roberto Cereja e Thereza Cochar Magalhães, 2009); Gramática da Língua Portuguesa (Pasquale e Ulisses, 2008). Esses livros são utilizados por escolas da rede privada do Distrito Federal, em nível do ensino médio.

Observa-se que, em dois dos três materiais didáticos analisados, há uma contextualização e uma linguagem mais acessível, no outro, há uma falta de contextualização e poucos exemplos, tendo uma abordagem tradicionalista do ensino e da descrição gramatical. Essa abordagem tradicionalista parece não contribuir para uma boa compreensão dos fatos gramaticais, de forma que se deve repensar os objetivos pedagógicos do material didático adotado nas escolas, já que os livros são a fonte principal de apoio a que os alunos recorrem e, portanto, é de fundamental importância que eles contribuam de forma positiva para facilitar a aprendizagem. 
Percebe-se uma preocupação por parte dos autores em trazer uma variedade de gêneros literários que componha os exemplos e procurar contextualizá-los, mas em determinadas seções, como a que foi analisada mais detalhadamente neste trabalho, não há uma contextualização que possa despertar o interesse e facilitar a assimilação do aluno. Há poucos exemplos e não há observações sobre temas essenciais, que possibilitem ao aluno ir além daquilo que ele vê puro e complexo. Apresenta-se o conceito e parece o suficiente.

Não há a preocupação em levar o estudante a fazer associações. O material didático não ensina o aluno a pensar e sim a fazê-lo decorar algo que provavelmente ele terá dificuldades para compreender. Os quadrinhos e os anúncios que são utilizados com enorme frequência só estão presentes na gramática nas partes simples, mas nos assuntos complexos, como as orações subordinadas, pouco se procura atrair a atenção do aluno de modo inovador

Verifica-se que, mesmo nos materiais didáticos que estão mais contextualizados, a parte mais interessante está concentrada no conceito, nem sempre abrangendo os exemplos e os exercícios. Especialmente quanto à Gramática Reflexiva, observa-se que a preocupação não é levar os alunos a refletir sobre o funcionamento da língua portuguesa nem ensinar novas habilidades lingüísticas que possibilitem ao aluno estender o conhecimento sobre a língua de maneira mais eficiente; dessa forma, não se deseja alterar padrões que o aluno já adquiriu nas séries antecedentes a origem e o porquê de se estudar determinado conteúdo. ${ }^{1}$

\subsection{Análise da Aplicação Orientada de Exercício Linguístico}

Os quatro alunos que fizeram parte desta pesquisa estão matriculados no primeiro e no segundo anos do ensino médio, sendo todos de classe média alta, com um histórico escolar predominantemente adquirido em escolas privadas de ensino

\footnotetext{
${ }^{1}$ Cabe ressaltar que essa crítica não se limita ao material didático utilizado no ensino médio. Analisando uma gramática do ensino fundamental utilizada por uma escola tradicional de Brasília, vê-se que não apresenta uma boa definição das orações subordinadas substantivas subjetivas, mas apenas diz que a oração subjetiva funciona como sujeito de verbos usados na $3^{\text {a }}$ pessoa do singular (com os seguintes exemplos: é bom, será necessário, convém etc.) e de verbos que se apresentam na voz passiva. Não se esclarece sobre o verbo de ligação nem sobre o predicativo. É uma definição confusa e imprecisa para o aluno.
} 
fundamental. Esses alunos estão sendo atendidos pela pesquisadora, em situação de reforço escolar.

Partindo dos questionamentos dos alunos e das dificuldades encontradas, foram realizadas algumas atividades para tentar compreender o motivo de tais dificuldades. Foram apresentados aos alunos exercícios referentes à classificação das orações subordinadas substantivas (incluindo-se no corpus também as orações que não são o objeto específico deste estudo). Foi proposto que eles realizassem os exercícios e externassem suas dúvidas e dificuldades.

No momento da correção desses exercícios, houve um diálogo em que eles puderam falar sobre as classificações que deram, como chegaram àquelas conclusões, se eles compreenderam porque classificar orações, se acharam importante saber classificar corretamente as orações, se souberam fazer relações e associações para chegar à classificação e se realmente aprenderam.

Para que se pudesse avaliar a problemática das subjetivas e predicativas, foram apresentadas vinte orações, das quais dez eram classificadas em subjetivas ou predicativas. O exercício foi dividido em duas partes, sendo que na primeira parte pretendia-se verificar se os alunos sentiam alguma dificuldade em identificar e separar a oração principal da subordinada, e na segunda parte fariam a classificação, para que se pudessem perceber todos os tipos de barreiras que eles encontravam.

No primeiro exercício havia seis orações, sendo que as alternativas (a) e (e) são classificadas como orações subordinadas substantivas predicativas e a alternativa (f) como oração subordinada substantiva subjetiva.

No segundo exercício as alternativas (a), (m) e (n) são classificadas como orações subordinadas substantivas predicativas e as alternativas (b), (h), (i) e (k) são classificadas como orações subordinadas substantivas subjetivas.

Seguem os exercícios:

\section{Orações Subordinadas Substantivas}

1) Separe a oração principal da oração subordinada, sublinhe-as e classifique-as:

a) A verdade é que ele não gosta do emprego.

b) O chefe fez questão de que nos retirássemos.

c) Ele sempre queria a mesma coisa: que a sua presença fosse notada.

d) Ninguém duvidava de que ele seria demitido. 
e) Sabemos que o senhor é um funcionário esforçado.

f) É preciso que o salário seja aumentado.

2) Sublinhe e classifique as orações subordinadas das sentenças a seguir:

a) O importante é que todos estejam aqui bem cedo.

b) É importante que todos estejam aqui bem cedo.

c) Todos nos pediram que trouxéssemos as crianças também.

d) Nunca me esqueci de que você me traíra.

e) Tenho aversão a que me critiquem.

f) O jovem advogado persuadiu o acusado de que a causa ainda não estava perdida.

g) Confesso-lhe que me detive alguns minutos olhando-o fascinado.

h) Parece que vai chover hoje à noite.

i) Nota-se que tudo mudou.

j) Vou lhe contar uma coisa: você está com as calças rasgadas.

k) É verdade que o professor não havia excluído ninguém do projeto.

l) Vi que eles estavam felizes com meu regresso.

m) O motivo da briga é que todos estão descontentes com ela.

n) O importante é que ele tivesse sido feliz.

Percebeu-se que não houve problemas na separação da oração principal e da oração subordinada. Constatou-se que os maiores problemas estão na classificação das orações com os verbos de ligação, em que ocorreram os maiores erros, pela dificuldade de distinguir a oração como predicativa ou subjetiva. Já nas alternativas que possuíam o verbo impessoal ou o verbo na voz passiva, não houve erros. Esses resultados mostram que, como antes de iniciar o conteúdo é feita uma revisão desses verbos, vinculados às situações em que uma determinada oração é classificada como subjetiva ou predicativa, percebeu-se que existe uma mecanização do processo de aprendizagem, para a qual cabe uma análise mais profunda em outro momento da pesquisa-

A maior ocorrência de erros nas orações subordinadas substantivas que possuem o verbo de ligação decorreu, segundo foi possível observar, do fato de que os alunos não souberam identificar a estrutura do período composto com a organização corresponde do predicado nominal (sujeito - verbo de ligação - predicativo do sujeito), e não perceberam a posição dos dois constituintes (sujeito e predicativo) em relação ao verbo 
que se encontrava nas sentenças, o que fazia com que eles ora classificassem as orações como predicativas ora como subjetivas, nem sempre corretamente. Concluiu-se que, principalmente nas alternativas (a) e (b) do exercício 2, a simetria dos predicados nominais com o verbo ser causou confusão na identificação do sujeito e do predicativo do sujeito, pois o que determina qual termo é sujeito e qual termo é predicativo do sujeito é a ordem dos constituintes e aspectos morfossintáticos como a presença ou a ausência do artigo definido diante da palavra importante, o que a torna sujeito na alternativa (a) e predicativo do sujeito na alternativa (b), respectivamente. Fatos como esses não estão contemplados na explicação da classificação dessas orações no material didático analisado, como já foi dito anteriormente.

\subsection{Conclusões parciais}

A análise dos livros didáticos adotados pelas escolas de ensino médio em que os sujeitos desta pesquisa estão matriculados mostra a coexistência de diferentes propostas metodológicas: uma em que há profunda articulação entre os eixos de leitura, escrita e análise lingüística, concorrendo para um desenvolvimento maior da leitura e da escrita; outra, em que a gramática vem desvinculada dos demais eixos e segue uma abordagem mais tradicionalista de classificação e reconhecimento.

Percebeu-se que os alunos tiveram dificuldades em classificar as orações do período composto, errando pela falta de compreensão da estrutura, não se atentando para a posição dos constituintes em relação ao verbo. Os verbos de ligação causaram maior confusão e dúvidas aos alunos, pois na realização dos exercícios simplesmente optavam por classificar em subjetiva ou predicativa sem nenhum critério. Afirmavam que sabiam que era uma ou outra, porém não sabiam diferenciá-las. 


\section{CONCLUSÃO}

Ao ensinarmos gramática, queremos que o aluno domine a língua e tenha competência nessa língua, mas, como diz Geraldi (1993, p. 17), é preciso entender que dominar uma língua não significa apenas incorporar "um conjunto de itens lexicais (vocabulário)", aprender "um conjunto de regras de estruturação de enunciados" e apreender "um conjunto de máximas e princípios" de como construir um texto oral ou escrito. Aprender a língua, seja de forma natural no convívio social, seja de forma sistemática em uma sala de aula, implica sempre reflexões sobre a linguagem, formulação de hipóteses e verificação do acerto ou não dessas hipóteses sobre a constituição e funcionamento da língua. Quando nos envolvemos em situações de interação, há sempre reflexão sobre a língua, pois é impossível usar e aprender a língua sem refletir sobre ela.

Propõe-se que, em termos de objetivos, o que se deve fazer é essencialmente um ensino produtivo para aquisição de novas habilidades lingüísticas, que exija alguma forma de reflexão, que o ensino das orações subordinadas substantivas possa ser voltado para uma gramática reflexiva, com o auxílio de uma gramática normativa para que, atreladas, elas possam estabelecer alguma relação de sentido, uma unidade de sentido para o texto como um todo e não em frases isoladas e abstraídas de qualquer contexto de comunicação, para que ocorra de fato uma aprendizagem significativa.

$\mathrm{Na}$ teoria da aprendizagem significativa apresentada no Capítulo 1 deste trabalho, Ausubel apresenta uma proposta em que a aprendizagem tenha como ambiente uma comunicação eficaz, que respeite e conduza o aluno a imaginar-se como parte integrante desse novo conhecimento através de elos, de termos familiares a ele. Através da palavra, o educador pode diminuir a distância entre a teoria e a prática na escola, capacitando-se de uma linguagem que ao mesmo tempo desafie e leve o aluno a refletir e sonhar, conhecendo a sua realidade e os seus anseios.

Retomando as idéias de Piaget observa-se que a posição de Ausubel é claramente cognitivista, já que sua teoria tem como foco básico o desenvolvimento cognitivo. Para ele, o cognitivo envolve a construção de estruturas mentais a partir das 
interações do sujeito com o meio. Essa construção envolve diferentes estágios que constituem um desenvolvimento universal e necessário.

Percebe-se que, para que a aprendizagem seja significativa, é preciso que os conteúdos aprendidos sejam lógicos e coerentes, mas também que tenham significação psicológica, e para isso o indivíduo tem que estabelecer uma ligação entre o novo conteúdo e seus conhecimentos prévios, de acordo com o desenvolvimento da inteligência.

Foi possível perceber que falta aos alunos pesquisados um conhecimento prévio significativo, já que se espera que um aluno do ensino médio tenha capacidade de identificar uma oração subordinada substantiva sem dificuldades, visto que aprendeu isso durante vários anos de sua vida escolar no nível fundamental.

Supõe-se que eles não compreenderam concretamente alguns conceitos básicos, como as relações de predicação, de predicativo do sujeito, dentre outros, problema que não se pode atribuir aos alunos, pois verificou-se que o próprio material didático apresenta limitações quanto ao desenvolvimento desses. Por exemplo, como se explica para um aluno que predicativo do sujeito não é termo essencial, nem integrante, nem acessório, se se pretende mostrar exatamente as relações que existem entre os termos, É isso o que acontece com a função de predicativo do sujeito, que não se encontra inserida em nenhuma dessas classificações dos termos da oração. Essa função sintática só aparece quando se trata dos tipos de predicado, mas não é claramente definida. Em Cunha e Cintra (1985, p. 129), o termo aparece como se os alunos já o conhecessem: “O predicado nominal é formado por um verbo de ligação+ predicativo". Essa imprecisão atrapalha que o aluno possa ter uma aprendizagem significativa já que não se compreende as informações e/ou definições apresentadas, pois não fazem sentido para eles.

Saber como os itens lexicais de uma língua se estruturam faz parte da competência lingüística que os alunos devem desenvolver, porém perceber que as sentenças de nossa língua não são o resultado de mera ordenação de itens lexicais em uma sequência linear, mas sim de uma organização hierárquica é algo difícil, que deve estar claramente explicitado no material didático. Conclui-se que, para ocorrer a aprendizagem clara, concreta e principalmente significativa, deve-se repensar o modo de como se está ensinando gramática, para não se continuar a cometer os mesmos erros e apenas repassar o que a gramática normativa regula e descreve, sem acrescentar nada 
que possa facilitar a assimilação e a aplicação dos conteúdos, independentemente de uma postura meramente classificatória. 


\section{REFERÊNCIAS BIBLIOGRÁFICAS}

AUSUBEL, D. P. A Aprendizagem Significativa: a teoria de David Ausubel. São Paulo: Moraes, 1982.

ARAGÃO, R. M. R., Teoria da Aprendizagem Significativa de David P. Ausubel. Tese de Doutoramento, Campinas, 1976.

BECHARA, E. Moderna Gramática Portuguesa. ed. rev. e ampl. e atual. conforme o novo Acordo Ortográfico. Rio de Janeiro: Nova Fronteira, 2009.

CEREJA, W. R.; MAGALHAES, T. C. Gramática Reflexiva: Texto, Semântica e Interação. São Paulo: Atual, 2009.

CIPRO, N. P. INFANTE, U. Gramática da Língua Portuguesa. São Paulo: Scipione, 2008 .

CUNHA, C.; CINTRA, L. F. Nova Gramática do Português Contemporâneo. Rio de Janeiro: Nova Fronteira, 1985

FARIA, W. de. Aprendizagem e Planejamento de Ensino. São Paulo: Ática, 1989.

GERALDI, J. W. Portos de Passagem. São Paulo: Martins Fontes, 1993

LUFT, C. P. Moderna Gramática Brasileira. 2ed.rev. e atual. São Paulo: Globo, 2002 
MOREIRA, M. A. \& Masini, E. F. S., Aprendizagem Significativa : a teoria de David Ausubel. São Paulo: Moraes, 1982.

PERINI, M. A. Gramática Descritiva do Português. 4ª ed. São Paulo: Ática, 2007.

PIAGET, J. Para Onde Vai a Educação? Rio de Janeiro: Olympio - UNESCO, 1973.

SARMENTO, L. L. Gramática em Textos. São Paulo: Moderna, 2005.

TRAVAGLIA, L. C. Gramática e Interação: uma proposta para o ensino de gramática. São Paulo: Cortez, 2008. 